\title{
Respiratory health effects of industrial air pollution: a study in east Lancashire, UK
}

\author{
Sarah E Ginns, Anthony C Gatrell
}

\begin{abstract}
Study objective - To determine whether there was a higher incidence of respiratory ill health in children living near to a cement works than in those from a different area, and if so whether the higher incidence was due to the use of a hazardous waste-derived fuel at the works.
\end{abstract}

Study design - A sample of the population of children living near the cement works (the study area) was compared with a sample of children living between 9 and $19 \mathrm{~km}$ away from the site (the control area). Setting - The cement works is located on the north eastern edge of a small rural town in east Lancashire.

Methods - Data were collected via the use of a health questionnaire. This was distributed through selected primary schools to families who had one or more children of primary school age (5-11 years).

Main results - The study and control populations were comparable in terms of response rates, gender, and socioeconomic indicators. There was no significant difference in the incidence of asthma (as diagnosed by a general practitioner) between the two areas when adjustment for hayfever was made. The incidence of sore throat was significantly higher in the case area, a difference not explained by other factors. For two other non-specific indicators of respiratory health (blocked nose and sore eyes) there was a significantly higher incidence in the study area, although hayfever and mould were also significant influences.

Conclusions - The results indicated that certain non-specific health indicators were more common in the children living near a cement works. This excess may be due to exposure to emissions from the site. However, it is not possible to draw firm conclusions because there are no epidemiological data predating the use of the hazardous waste derived fuel.

( $(\mathcal{F}$ Epidemiol Community Health 1996;50:631-635)

Department of Geography, Lancaster University, Lancaster LA1 4YB

$S$ E Ginns

A C Gatrell

Correspondence to: Dr A C Gatrell.

Accepted for publication April 1996
Anthropogenic (man made) air pollution has long been implicated as a major contributor to poor health, and has been recognised as an exacerbating factor when it is present with other contributory factors such as exposure to cigarette smoke and natural allergens such as pollen. However, direct causality is notoriously difficult to prove when considering the range of potential pollution sources and the almost infinite variety of chemicals to which the public is often exposed. Despite these difficulties some studies ${ }^{12}$ have shown evidence of an association between air pollution and mortality and morbidity, even when adjustment for other risk factors is made. The present research studies the possible health effects of living near a cement works and is partly motivated by concerns expressed by members of the local community living near to the works. The 1990 s have seen a rise in the number of local environmental concern groups, not only in the United Kingdom but throughout the industrial world. The vocal expression of such groups creates further difficulties in seeking to overcome potential "sensitisation" bias.

The production of cement from limestone, clay, and gypsum is inevitably a dirty, dusty process but it is necessary for the efficient functioning of the construction industry. The chemical conversion of the raw materials into cement requires the heating of these materials to temperatures exceeding $1400^{\circ} \mathrm{C}$ in specially designed kilns. Traditionally, this heat has been provided by burning fossil fuels, with just one of the major cement manufacturers in Britain consuming 400000 tonnes of coal every year. Concern about the earth's fossil fuel reserves has generated a search for other fuel sources for some years. This, coupled with the need to find alternative disposal routes away from landfill, particularly for hazardous wastes, has led to the cement manufacturing industry being a prime mover in the push to use alternative fuels derived from such wastes. However, the choice of such fuels has not proved popular with local communities living in the vicinity of those cement works using them.

The site upon which the present study is based has been using, since May 1992, what is termed a recycled liquid fuel (RLF) to substitute for $50 \%$ of its coal consumption. RLF is manufactured from hazardous waste organic materials, including solvent-based wastes and hydrocarbons from other industries. It can contain ground and pulverised solids and these are blended into the liquid carrier. Local residents living near to the cement works in question have long complained about the plume of emissions from the main chimney on the site coming to ground over their homes. The owners of the site have acknowledged that there has been a problem with plume grounding for several years and since well before they started using the RLF. However, perhaps understandably, the use of a hazardous wastederived fuel at the site has generated a series of public debates about the possible health implications. The present paper is concerned 
only with an epidemiological survey, the policy implications are considered elsewhere. ${ }^{3}$

Many of the local residents living around the cement works have complained about the plume of emissions and have reported an increased incidence of headaches, sore eyes, sore throats, runny or blocked noses, and wheezing or asthma attacks, claimed to be a result of the alternative fuel source. This study aimed to assess the incidence of non-specific (mostly respiratory) health effects in the local community through the use of epidemiological methods. Our null hypothesis was that, after suitable standardisation, no excess prevalence of asthma or of other, non-specific symptoms would be found in residents in the area near the cement works compared with elsewhere in the county.

\section{Methods \\ SETTING}

The cement works is situated on the north eastern edge of a small rural town in the Ribble valley in East Lancashire. Most residential property in the town lies to the south west of the site, with small villages lying to the north east and north of the site. The prevailing wind in the area is south westerly and this tends to carry any plume of emissions along the valley. The exact chemical composition of the emissions arising from the use of hazardous wastederived fuels cannot be determined due to variation in the composition of the fuels. However, tests have indicated that in addition to the standard emissions of sulphur dioxide, nitrogen dioxide, and particulate matter arising from the combustion of coal, these alternative fuels give off more complex chemicals when burned. These include complex organic compounds and heavy metals, although levels of these are lower than accepted levels. ${ }^{4}$

\section{STUDY DESIGN AND ETHICAL APPROVAL}

A cross sectional study was used as this is considered the most appropriate design to assess possible health effects due to exposures that have been stable over time. ${ }^{5}$ A questionnaire was used to collect data for a sample of primary school children in the area. It was decided not to conduct the survey among the adult or teenage population in order to minimise the confounding effects of smoking, drinking, and possible drug abuse. Children of primary school age (5-11 years) are unlikely to be exposed directly to these risk factors, and so a focus on this age group avoids the serious confounding of a possible association between respiratory morbidity and air pollution. Indirect exposure, for example to cigarette smoke, is addressed in the questionnaire and controlled for statistically.

Our study population consisted of all the pupils from three primary schools in the area next to the cement works. The largest of these schools was in the same town and the other two schools were situated in two nearby villages, one $1 \mathrm{~km}$ east north east of the site and one $2 \mathrm{~km}$ north of the site. The control popu- lation consisted of all the pupils from three primary schools situated well away from, and south of, the cement works. One school was in a small town $9 \mathrm{~km}$ south of the works and the other two schools were situated in two villages $19 \mathrm{~km}$ south west of the site.

The questionnaires were distributed to each pupil via their class teachers and then collected by the school within a specified period of time (10 days). Because of the young age of the children concerned, parents or guardians were asked to complete the questionnaire for them. Before the questionnaires were distributed approval was sought and obtained from East Lancashire Health Authority Ethics Committee.

DATA SOURCES: SOCIOECONOMIC DATA

To ensure that the children surveyed came from areas of broadly similar socioeconomic status, and that any differences in health status between the two populations would be unlikely to be due to very different socioeconomic settings, data from the 1991 census were collected. ${ }^{6}$ For census enumeration districts (EDs) in both the case and control areas we examined data on the following variables: levels of owneroccupation of housing, car ownership, the number of dependent children, levels of unemployment, lone parenthood, limiting long term illness, and overcrowding.

\section{DATA SOURCES: QUESTIONNAIRE DATA}

The questionnaire sought information about the following: child's age and gender; general health and allergies, including whether the child had hayfever, eczema, food or other allergies; incidences of asthma in either of the parents; exposure in the home to tobacco smoke; socioeconomic status; nature of heating in the home; problems with condensation and mould; and presence of pets. The questionnaire asked whether asthma had been diagnosed by a doctor within the last three years. Information was sought on a series of non-specific symptoms, and whether the child had suffered from any of them during the previous three months. These symptoms included the following: runny nose, blocked nose, sore eyes, sore throat, dry cough, cough with phlegm, skin rash, headache, and lack of energy. Some information was sought on symptoms (such as ear infection, stomach ache, and nausea) that were unlikely to be associated with air pollution.

The survey took place during June 1995.

\section{ANALYSIS OF DATA}

Children from the schools near the cement works were designated as living in "area 1", while those from the control area were deemed to reside in "area 2". We treated various health symptoms as response variables in a logistic regression analysis, ${ }^{7}$ with a wide range of variables from the questionnaire as potential covariates. Area of residence (study or control) was coded as a binary variable. Statistical analysis used GLIM. ${ }^{8}$ 
Table 1 Results of logistic regression analysis of questionnaire data collected from sample of children in the study and control areas

\begin{tabular}{llcc}
\hline Symptom & Covariate & Odds ratio & $(95 \%$ CI $)$ \\
\hline Asthma & Hayfever & 84.1 & $(0.67,10524)$ \\
& Age & 2.15 & $(1.29,3.58)$ \\
& Hayfever/Age & 0.49 & $(0.29,0.84)$ \\
Sore throat & Area & 1.83 & $(1.15,2.91)$ \\
Blocked nose & Hayfever & 4.81 & $(2.23,10.36)$ \\
& Mould & 2.82 & $(1.25,6.35)$ \\
& Area & 1.58 & $(1.00,2.48)$ \\
Sore eyes & Hayfever & 26.76 & $(11.26,63.60)$ \\
& Mould & 2.04 & $(1.05,3.98)$ \\
& Area & 2.67 & $(1.01,7.09)$ \\
\hline
\end{tabular}

\section{Results}

Of the 656 questionnaires distributed to the primary school pupils in both the study and control populations, $55.2 \%$ were returned to the schools for collection. The response rate was $55.1 \%$ for children in the study area and $60.8 \%$ for the control population.

Logistic regression models fitted to selected symptoms identified a set of variables that each had a statistically significant influence on the prevalence of that symptom or illness. We calculated the adjusted odds ratio (OR) and the associated confidence intervals for each covariate, in order to examine the relative influence of each variable on the likelihood of having that symptom. Initially, each variable was entered as a single covariate, with others added in an effort to gain explanatory power. Variables were retained if they had significant OR $(\mathrm{p}<0.05)$.

Results for four symptoms, expressed as the best fitting model, are shown in table 1. Asthma prevalence is associated with hayfever and with age, but there is a significant interaction between age and hayfever; as children get older the risk of their being diagnosed asthmatic is much greater if they have hayfever than if they do not. There is a statistically significant difference in asthma prevalence between the two areas, but this vanishes when these two obvious covariates (age and hayfever) are included. Hayfever is also a risk factor for blocked nose and sore eyes, but in both cases the presence of mould in the home and the home location of the child (area 1 or 2) add independent explanatory power. Only area as a covariate is a significant risk factor for sore throat; hayfever has no effect on the incidence of this symptom, nor does any other variable.

For none of the symptoms considered here did we find that covariates such as exposure to cigarette smoke, presence of furry animals, or type of heating had any significant additional effect.

\section{Discussion}

The survey achieved a $55 \%$ response rate, which is acceptable for an initial mailing but not wholly adequate for extrapolating to the complete population of children in the study area. Due to the limited time span available (before the schools closed for the summer vacation) we were not able to carry out follow up mailings to non-responders, as would be the normal procedure for a longer term health study. Despite the low response rate there is no compelling evidence of differential response between study and control areas. Indeed, while we might expect a better response rate in an area where people had expressed concerns about health - and were attributing perceived ill health to a point source of pollution - the response was actually better in the control area.

The results from the logistic regression analysis indicate that the incidence of the sore throat symptom is influenced only by the area variable; that is, the higher incidence in the study area is associated with some difference between the study and control areas. Although it is impossible to prove direct causality in epidemiological studies, we suggest that the above symptom difference between the two areas could be associated with emissions from the cement works. The results obtained for the blocked nose symptom indicate that it is associated with the area variable and also with the presence of mould in the home and whether or not the child suffers from hayfever. While these results may also suggest some association with the location of the cement works, the odds of a child suffering from a blocked nose are more significantly influenced by mould and hayfever. The strong influence of hayfever on the blocked nose symptom is not surprising, given that the survey was conducted during the month of June when the weather was dry and the pollen counts were high. The association of the blocked nose symptom with the presence of mould in the home (but not with the presence of condensation or visible dampness) supports the findings of a previous study relating to damp housing and respiratory symptoms. ${ }^{9}$ Results from a study on the health effects of living next to a coking works ${ }^{10}$ gave the symptom of sinus trouble as most prevalent nearest to that site, a finding supported in the present study.

The sore eyes symptom was also found to be significantly associated with the area variable, again indicating some possible influence of the emissions from the cement works. As with the blocked nose symptom, the other significant variables were hayfever and mould. Again we should not be surprised by the very strong impact of the hayfever variable on the sore eye symptom, as sore and runny eyes are one of the major symptoms of hayfever, caused by irritation of the mucus membranes of the eyes. The influence of mould on the eyes is less straightforward to explain, but it could be that mould spores have a similar effect on the mucus membranes of the eyes as pollen and thus give similar symptoms to hayfever.

These results seem to indicate that there is a higher incidence of hayfever in the study area than in the control area and that this has an impact on the above symptoms. However, because both the study and control schools are in similar rural locations we might expect that a possible influence of high pollen levels or the use of agricultural chemicals on hayfever or other allergic states would be similar in both areas, so we may have expected the hayfever incidence to be similar in both areas. Despite the fact that incidence of hayfever is higher in the case area there is still an area effect on the 
symptoms of sore throat, blocked nose, and sore eyes and this would indicate some remaining association with the presence of the cement works in the case area. Anecdotal reports from environmental health officers and local residents have suggested that when the previously mentioned plume grounding occurs in the vicinity of the site, it can cause considerable irritation of the mucus membranes of the eyes, nose, and throat. The results of the survey reported here seem to support these observations.

One of the major concerns among the residents near the cement works was an apparent increase in the incidence of asthma in the area - that is, an increase in the number of diagnosed asthmatics. It was therefore of interest to see if the results of this study indicated a higher incidence of asthma (as diagnosed by a general practitioner) in the study area than in the control area. When the logistic regression model was fitted for asthma, the area variable had a significant effect, but this effect disappeared when the effects of age and hayfever were added to the model. There is no obviously increased prevalence of asthma in the population near to the cement works. Asthma has previously been found to be associated with hayfever ${ }^{11}$ and the results from the present survey support this finding. We also found that there was an interaction between the hayfever and age variables and asthma, indicating that as children get older and suffer from hayfever, the higher is the likelihood of having asthma. If the child does not have hayfever the age effect is less marked. The interaction between age and hayfever could be because susceptible individuals become more sensitive to the allergens which give them hayfever the longer they are in contact with the sensitising effects of, for example, air pollution. These more susceptible individuals may then be more likely to suffer from other allergy related disease states such as asthma. This could explain why the area effect becomes insignificant when age and hayfever are added to the logistic regression model.

The apparently increased prevalence of asthma has been the subject of much speculation during recent years, with some argument as to whether the increase is due to a true increase in the incidence ${ }^{12}$ or to increased use of the asthma diagnosis. ${ }^{13}$ Because of the seriousness of asthma and the distress it can cause to sufferers and their families, there has been considerable research into the aetiology of asthma. It is interesting to consider the results of previous studies on asthma in the light of our results. The coking works study ${ }^{10}$ found no difference in asthma prevalence between areas of increasing distance from the site and this was a similar result to that in the present study.

While mould was a significant factor in the incidence of blocked noses and sore eyes, there was no such influence of mould on asthma. This result does not corroborate the results of a previous study ${ }^{9}$ which found a strong association between the presence of mould in the home and the incidence of asthma.
Several studies have been directed at assessing the suggested link between passive smoking and asthma in children and some have shown that there does indeed appear to be an association between exposure to tobacco smoke and respiratory distress in children. ${ }^{1415}$ However, this link is not always corroborated, ${ }^{11}$ and in the survey reported here exposure to cigarette smoke was not a significant factor in asthma prevalence.

Several previous studies have focussed on the possible effects of particulate air pollution on the incidence of asthma and other respiratory problems, and many have indicated that there is a strong association between exposure to particulate pollution and asthmatic symptoms. ${ }^{16-19}$ This link between asthma and industrial air pollution has been postulated elsewhere in connection with emissions from another cement works burning hazardous waste-derived liquid fuels, and a study in that area seemed to show an increase in the incidence of asthma close to the site. ${ }^{20}$ To assess whether these fuels create long term health hazards requires extensive investigation in which results from several similar study areas are pooled and compared with other areas matched, as here, for socioeconomic status.

In spite of the results suggesting that, for asthma, there is no significant difference between the two areas of interest when known risk factors are controlled for, there was an increased prevalence of certain non-specific symptoms in the area nearest to the cement works in East Lancashire. These symptoms are thought to be a good indicator of long term exposure to higher levels of air pollution. ${ }^{21}$ Although other factors play a part in the incidence of these symptoms, there seems to be some association with the proximity to the cement works. Current work is being undertaken to fit binary regression model ${ }^{22}$ to the incidence of symptom prevalence around the cement works in order to see if there is raised relative risk close to the site.

We noted earlier that the motivation for the study derived from health concerns expressed by residents living in the vicinity of the cement works. This raises the issue of whether our results are affected by "sensitisation bias"; in other words, has the vocal campaign mounted by local residents made study respondents very aware of the possible health risks due to the cement works and therefore predisposed them to respond to our questionnaire in a particular way?

The issue of awareness or sensitisation bias is discussed at length in further research ${ }^{23}$ arising out of the Monkton Coking Works study ${ }^{10}$ referred to earlier. Essentially, the kind of epidemiological study we have conducted regards local concerns and beliefs as a "nuisance", the effect of an already sensitised population and an "obstacle to scientific enquiry" 23 that seeks to uncover "real" health effects. A more socially informed epidemiology, however, would wish to give lay beliefs some prominence, to regard local concerns as data that are as valid as those derived from more formal questionnaires such as that used in the present study. One mo- 
tivation for doing so is that anxieties about possible effects on health may well contribute to stress, and that this itself has negative health consequences. ${ }^{23}$ In the more qualitatively based social research on lay beliefs among those likely to be affected, and those unaffected, by pollution from the Monkton Coking Works, it was found that the concerns of those living near the plant were indeed supported by epidemiological evidence of ill health. This was not seen as sensitisation bias, partly because respondents did not report generalised respiratory ill health; rather, they reported particular kinds of respiratory symptoms. Of interest in the present study is that such specific symptoms, notably sinus trouble among children, are similar to those which we have found to be raised in our study area. Sensitisation bias might be expected to lead to increased reports of all types of respiratory symptoms. This does not appear to be the case here, or in the related Monkton Coking Works study. We have not ourselves collected data on lay beliefs in our study and control areas but, clearly, epidemiologists need to acknowledge more fully the role that such beliefs can play in seeking to understand the health consequences of exposure to environmental contamination.

1 Dockery DW, Pope CA, Xu X, et al. An association between air pollution and mortality in six US cities. $N$ Engl f Med 1993;329:1754-59.

2 Dunn CE, Woodhouse J, Bhopal RS, Acquilla SD. Asthma and factory emissions in northern England: addressing public concern by combining geographical and epidemiological methods. $f$ Epidemiol Community Health 1995;49:395-400. 3 Ginns SE. Environment and health: a respiratory health survey
of primary school children in east Lancashire. Lancaster. Lancaster University, 1995, MSc Dissertation.

4 Slater D. The burning of secondary liquid fuels in cement kilns. Memorandum by Her Majesty's Inspectorate of Pollution in House of Commons Environment Committee 2nd Report on The Burning of Secondary Liquid Fuel in Cement Kilns. London: HMSO 1995:79-86.
5 Dockery DW. Epidemiologic study design for investigating respiratory health effects of complex air pollution mixtures. Environ Health - Perspect 1993; 101(suppl):187-91.

6 Dale A, Marsh C, eds. The 1991 census user's guide. London: HMSO 1993.

7 Kelsey JL, Thompson WD, Evans AS. Methods in $o b$ servational epidemiology. New York; Oxford University Press, 1986.

8 Aitkin M, Anderson D, Francis B, Hinde J. Statistical modelling in GLIM. Oxford; Clarendon Press, 1989.

9 Strachan DP, Sanders CH. Damp housing and childhood asthma; respiratory effects of indoor air temperature and relative humidity. $\mathcal{F}$ Epidemiol Community Health $1989 ; 43$ 7-14.

10 Bhopal RS, Phillimore P, Moffatt S, Foy C. Is living near a coking works harmful to health? A study of industrial air pollution. $\mathcal{F}$ Epidemiol Community Health 1994;48:237-47.

11 Kaplan BA, Mascie-Taylor CGN. Biosocial factors in the epidemiology of childhood asthma in a British national sample. 7 Epidemiol Community Health 1985;39:152-6.

12 Burney PGJ, Chinn S., Rona RJ. Has the prevalence of asthma increased in children? Evidence from the national study of health and growth 1973-86. BMF 1990;300: study of $1306-10$.

13 Strachan DP, Ross Anderson H. Trends in hospital admission rates for asthma in children. $B M F$ 1992;304: 819-820.

14 Forastiére F, Corbo GM, Michelozzi P, et al. Effects of environment and passive smoking on the respiratory health of children. Int $\mathcal{F}$ Epidemiol 1992;21:66-73.

15 Agudo A, Bardagi S, Romero PV, González CA. Exercise induced airways narrowing and exposure to environmental tobacco smoke in schoolchildren. Am 7 Epidemiol 1994; 140:409-17.

16 Arden Pope III C, Dockery DW. Acute health effects of PM10 pollution on symptomatic and asymptomatic chilPM10 pollution on symptomatic and asymp
dren. Am Rev Respir Dis 1992;145:1123-8.

dren. Am Rev Respir Dis 1992;145:1123-8.
17 Schwartz J, Slater D, Larson TV, et al. Particulate air pollution and hospital emergency room visits for asthma in Seattle. Am Rev Respir Dis 1993;147:826-31.

18 Abbey DE, Peterson F, Mills PK, Lawrence Beeson W. Long-term ambient concentrations of total suspended particulates, ozone and sulfur dioxide and respiratory symptoms in a non-smoking population. Arch Environ Health 1993;48:33-46.

19 ENDS Reports. Strengthening link between particulates and health risks. ENDS 1994;237:3.

20 ENDS Reports. Health studies point the finger at industrial air pollution. ENDS 1995;244:22-5.

21 Bates DV. Health indices of the adverse effects of air pollution: the question of coherence. Environ Res 1992;59: 336-49.

22 Diggle P, Rowlingson BS. A conditional approach to point process modelling of elevated risk. $\mathcal{F} R$ Stat Soc Ser $A$ 1994;157:433-40.

23 Moffatt S, Phillimore P, Bhopal R, Foy C. "If this is what it's doing to our washing, what is it doing to our lungs?" Industrial pollution and public understanding in northeast England. Soc Sci Med 1995;41:883-91. 